\title{
RETROPERITONEAL NEUROFIBROMA: A CASE REPORT
}

\author{
Vinod Tamaknand ${ }^{1}$, Sandhya Gupta ${ }^{2}$, Rajesh Godara ${ }^{3}$, Pradeep Garg ${ }^{4}$, Amit Dangi ${ }^{5}$
}

\section{HOW TO CITE THIS ARTICLE:}

Vinod Tamaknand, Sandhya Gupta, Rajesh Godara, Pradeep Garg, Amit Dangi. "Retroperitoneal Neurofibroma: A Case Report". Journal of Evolution of Medical and Dental Sciences 2015; Vol. 4, Issue 84, October 19;

Page: 14741-14744, DOI: $10.14260 /$ jemds/2015/2097

ABSTRACT: A 40yr. old female presented with a large solitary neurofibroma in retroperitoneum without any specific features. CECT suggested possibility of gastrointestinal stromal tumor (GIST). Tumor was completely excised. Histopathology revealed Neurofibroma. Retroperitoneal neurofibromas presenting without specific features/Von Recklinghausen's disease are quite rare.

KEYWORDS: Retroperitoneal neurofibroma.

INTRODUCTION: Nerve sheath tumours (NST) are a subclass of soft tissue neoplasms that include benign and malignant schwannomas and neurofibromas. Presentation as retroperitoneal tumors is uncommon and neurofibromas still rarer. Solitary neurofibroma without von Recklinghausen's disease is the rarest presentation of all neurofibromas. Most NST's are small solitary and benign and rarely exceed $6 \mathrm{~cm}$ in diameter. ${ }^{1}$ Symptoms do not appear until they have attained gigantic dimension or start compressing surrounding structure. We describe a case of solitary neurofibroma which was diagnosed by histopathology after complete excision.

CASE REPORT: A 40 year old Indian female presented with complaint of vague abdominal pain for one year. Pain was of moderate intensity, localised to upper abdomen and episodic in nature. Family history was negative for Von Recklinghausen's disease. Physical examination did not contribute much. Haematological and biochemical investigations were normal. Ultrasound showed a mass lesion of size $106 \times 96 \mathrm{~mm}$ in lesser sac did not show any significant flow on colour doppler. A diagnosis of hydatid cyst or gastrointestinal stromal tumor (GIST) was considered. CT demonstrated a large well defined soft tissue attenuation mass showing central necrotic area and homogeuous nodular enhancement in lesser sac in relation to posterior wall of stomach suggesting possibility of GIST. Exploratory laparotomy was performed. Large well circumscribed mass measuring $11 \times 10 \times 7 \mathrm{~cm}$ in retroperitoneum close to upper pole of left kidney and pancreas, but separate from both these organs was noted. Tumour was resected in its entirety. Cut surface was yellowish brown with small cystic areas. Representative microsections on examination revealed fusiform cells forming partially interwoven bundles in some areas. Immunohistochemistry for S-100 protein and Vimentin was diffusely positive suggestive of benign retroperitoneal neurofibroma. Postoperative period was eventless. 

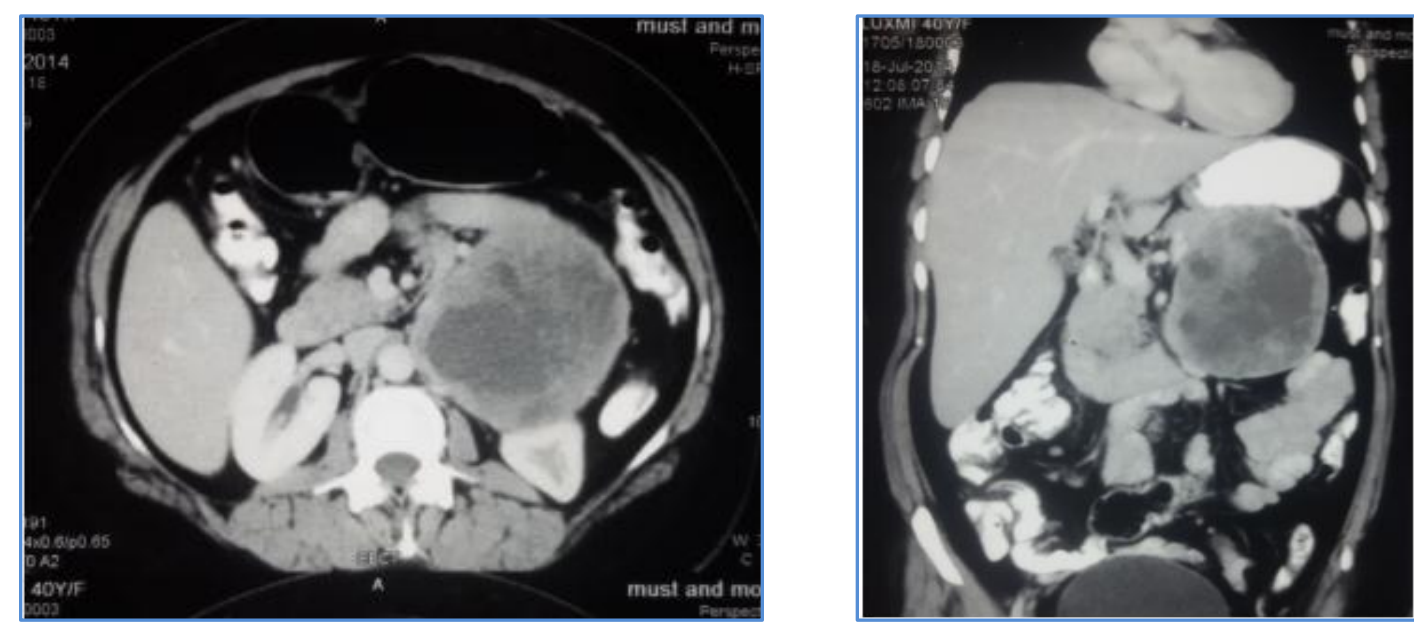

Fig. 1 \& 2: Showing CECT film in Transverse and Coronal
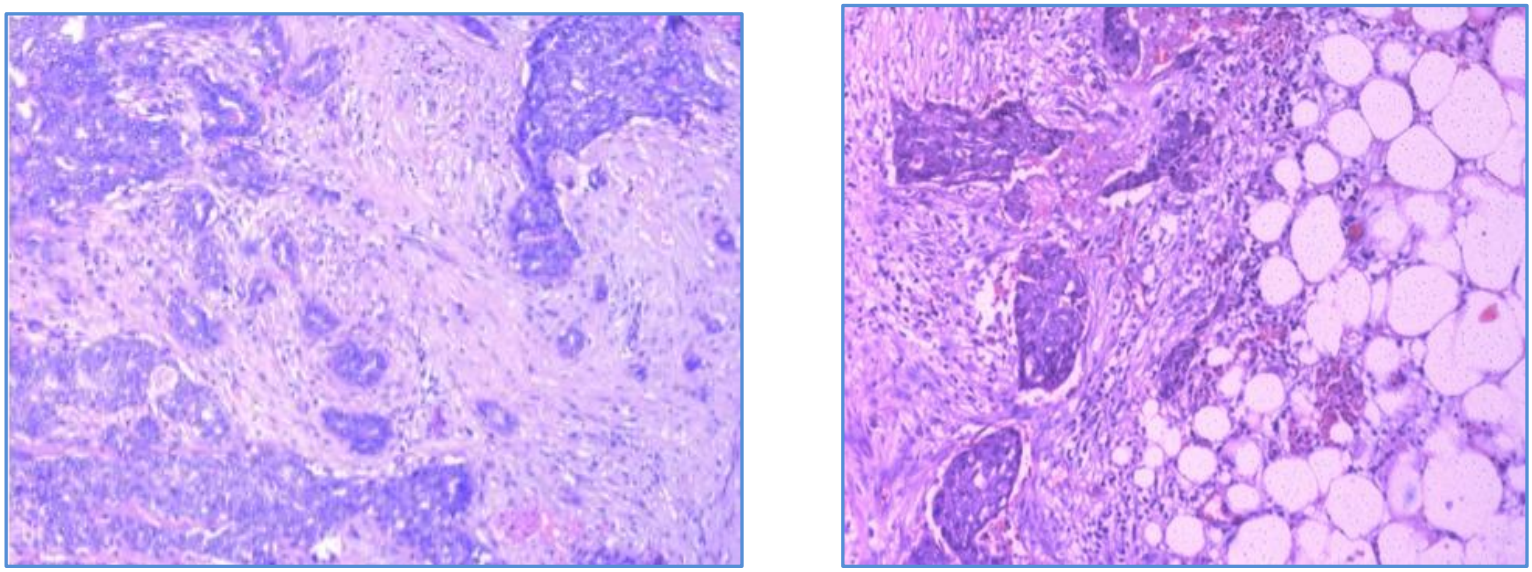

\section{Fig. 3 \& 4: Showing HPR of Retroperitoneal Neurofibroma}

DISCUSSION: Nerve sheath tumours contribute about $4 \%$ of retroperitoneal tumors. ${ }^{2}$ Neurofibromas are often multiple, plexiform and found in association with Neurofibromatosis 1. Von Recklinghausen's disease or neurofibromatosis 1 is an autosomal dominant disorder with multiple neurofibromas and schwannomas, along with cafe au lait spots and axillary freckling. In absence of this disease neurofibromas are solitary and don't turn malignant even though 4-11\% of neurofibroma associated with NF1 do undergo malignant degeneration. ${ }^{3}$ A solitary neurofibroma represents either a sporadic case or a carrier of defective gene with only mild clinical presentation. ${ }^{4}$ Therefore all patients should be examined for stigmata of neurofibromatosis.

Solitary neurofibromas are slow growing tumours which lack a well-defined capsule and an identifiable parent nerve. These tumours generally have equal gender distribution and present between $3^{\text {rd }}$ and $6^{\text {th }}$ decade of life. ${ }^{5}$ Clinically they present with symptoms of compression rather than invasion. They can present as asymptomatic abdominal mass or can cause pain which can be colicky in case of obstruction of bowel, ureter, biliary system or neuralgia due to involvement of nerve and bone. 
Gastrointestinal symptoms like abdominal discomfort, nausea, vomiting, constipation, obstipation or neurological symptoms like neuralgic pain, hypoesthesias and paraesthesias can also be seen.

Diagnosis of a retroperitoneal neurofibroma is difficult to establish preoperatively as neuroimaging is not specific. On CT neurofibromas are smooth, rounded, homogeneously hypoattenuating masses. MRI shows a target like enhancement pattern with attenuation in the centre known as the central dot sign. Dot sign corresponds to edema, microcysts, foam cells, hyalinization of blood vessels, old hemorrhage and dystrophic calcification.6,7 Diagnosis can be confirmed only on histopathology. CT or USG guided aspiration biopsy is the only way to confirm diagnosis preoperatively. It is not advisable though, because aspirate usually consists of highly pleomorphic cells which are difficult to interpret and procedure itself is fraught with complications like infection and haemorrhage.

Complete surgical excision is the treatment of choice for retroperitoneal nerve sheath tumors. Residual disease might lead to recurrence of tumor and its symptoms or malignant transformation. ${ }^{8}$ Surgical resection is challenging because sometimes there is nerve entrapment by the tumor and it becomes impossible to remove tumor without sacrificing the nerve. In case of huge masses, if malignancy cannot be ruled out, enbloc excision of margins or organs around the tumor should be done. Recurrence rate in wide excision of tumor is $11.7 \%$ as compared to $72 \%$ in only margin excision. ${ }^{9}$

CONCLUSION: Retroperitoneal neurofibroma is a histopathological diagnosis. Because of its varied imaging appearance, interpretation of imaging results is often difficult. Differentiating between benign and malignant disease radiologically too is difficult. It is imperative that extensive surgery for a benign disease is avoided and radical surgery for a malignant disease is undertaken.

\section{REFERENCES:}

1. Stout AP: The peripheral manifestations of the specific nerve sheath tumor (neurilemmoma). Am J cancer 1935; 24:751.

2. Van Roggen JF, Hogendoorn PC. Soft tissue tumours of the retroperitoneum. Sarcoma 2000; 4: 17-26.

3. Zimmerman RA, Bilaniuk LT: Imaging of tumors of the spinal canal and cord. Radiol Clin North Am 1988; 26: 965-1007.

4. Seppala MT, Haltia MJJ, Sankila RJ, Jaaskelainen JE, Heiskanen O: Long term outcome after removal of spinal neurofibroma. J Neurosurg 1995; 82: 572-7.

5. Salah S, Horcajada J, Perneczky A: Spinal neuromas - a comprehensive clinical and statistical study on 47 cases. Neurochirigia (Stuttg) 1975;18: 77-84.

6. Gouliamos AD, Kontogiannis DS, Androulidakis EJ, Kalovidouris AE, Vlahos LJ, Papavasiliou CG: spinal neurilemmomas and neurofibromas: Central dot sign in postgadolinium MRI. J Comput Assist Tomogr 1993;17: 446-8.

7. Varma DG, Moulopoulos A, Sara AS, Leeds N, Kumar R, Kim EE, Wallace S: MR imaging of extracranial nerve sheath tumors. J Comput Assist Tomogr 16: 448-53, 1992.

8. Hurley L, Smith J, Larsen C, Silvennan M. Multiple retroperitoneal schwannomas: Case report and review of the literature. J Urol 151: 413-6, 1994. 


\section{CASE REPORT}

9. Bose B. Primary malignant retroperitoneal tumors: analysis of 30 cases. Cancer J Surg 22(3): 215-20, 1979.

\section{AUTHORS:}

1. Vinod Tamaknand

2. Sandhya Gupta

3. Rajesh Godara

4. Pradeep Garg

5. Amit Dangi

\section{PARTICULARS OF CONTRIBUTORS:}

1. Junior Resident, Department of General Surgery, Pt. B. D. Sharma PGIMS.

2. Junior Resident, Department of General Surgery, Pt. B. D. Sharma PGIMS.

3. Professor, Department of General Surgery, Pt. B. D. Sharma PGIMS.

\section{FINANCIAL OR OTHER}

COMPETING INTERESTS: None
4. Senior Professor, Department of General Surgery, Pt. B. D. Sharma, PGIMS.

5. Senior Resident, Department of General Surgery, Pt. B. D. Sharma PGIMS.

\section{NAME ADDRESS EMAIL ID OF THE}

\section{CORRESPONDING AUTHOR:}

Dr. Vinod Tamaknand,

Doctor Hostel Room No. 174,

PGIMS,

Rohtak-124001,

Haryana, India.

E-mail: vinodtamaknand@gmail.com

Date of Submission: 24/09/2015.

Date of Peer Review: 25/09/2015.

Date of Acceptance: 09/10/2015.

Date of Publishing: 19/10/2015. 